\title{
Assessment of Transformer Cellulose Insulation Life Expectancy Based on Oil Furan Analysis (Case Study: South African Transformers)
}

\author{
Bonginkosi Allen Thango*, Jacobus Andries Jordaan , Agha Francis Nnachi \\ Department of Electrical Engineering, Tshwane University of Technology, Emalahleni, 1034, South Africa
}

\begin{tabular}{l} 
A R T I C L E I N F O \\
\hline Article history: \\
Received: 04 June, 2021 \\
Accepted: 21 August, 2021 \\
Online: 13 November, 2021
\end{tabular}

Keywords:

Ageing

Oil

Transformer

Dissolved Gas Analysis (DGA)

Degree of polymerization (DP)

A B S T R A C T
The ageing of oil-immersed power transformers triggers several defects and damages in the
insulating materials, particularly in the cellulose insulation. The decomposition of the
cellulose paper produces dissolved gases into the insulating oil, in which the Dissolved Gas
Analysis (DGA) of the oil samples can provide insights to incipient faults sustained by the
transformer as well as the status of the insulation. The condition of the cellulose insulation
can be established by the measurement of the Degree of Polymerization (DP). In some
instances, when the DP is intricate to measure, the estimation can be realized by collating
information with respect to oil Furan analysis (2-furfuraldehyde (2FAL)). In this work,
regression analysis based on 120 transformer oil samples is developed to establish new
formulae by generating an analogy between the DP and 2FAL to indicate the status of the
cellulose insulation and percentage of remnant life expectancy. In present study, five
different transformers are tested using the proposed formulae to compute the DP based on
the $2 F A L$ concentrations. The results, are compared with measurement results and four other
existing models. The results indicate an error of estimate of less than $2 \%$ and 1\% against the
measured DP.

decomposition of the cellulose paper that disseminate into the transformer oil. In measuring the furan concentration on the transformer oil, then the cellulose paper conditions can be ascertained. A rigorous method to assess the tensile strength in the cellulose paper that is intricately connected to cellulose insulation strength of a transformer is unearthing the Degree of Polymerization (DP) of the insulation. However, it is infeasible to obtain the paper samples from a transformer that is in-service, particularly paper samples in winding hotspot areas that are typically localized in the centre of the transformer steel tank. A number of researchers [11-14] have concluded that there is a remarkable connection between the DP and furan concentration, specifically 2-Furaldehyde (2FAL). The benefit of analysing the 2FAL concentration correlated to the DP is that the transformer oil samples can be appropriately extracted from the unit in-service without engendering any impairment to the transformer.

The most common procedure in measuring Furanic compounds in the transformer oil is recommended by the standard published in [15]. In view of the fact that this procedure necessitates particular expertise and high-end equipment, utility owners and manufacturers subcontract the Furan test to certified service enterprises. The utilisation optical spectroscopy techniques is also 
more and more notable in the Southern African transformer condition monitoring.
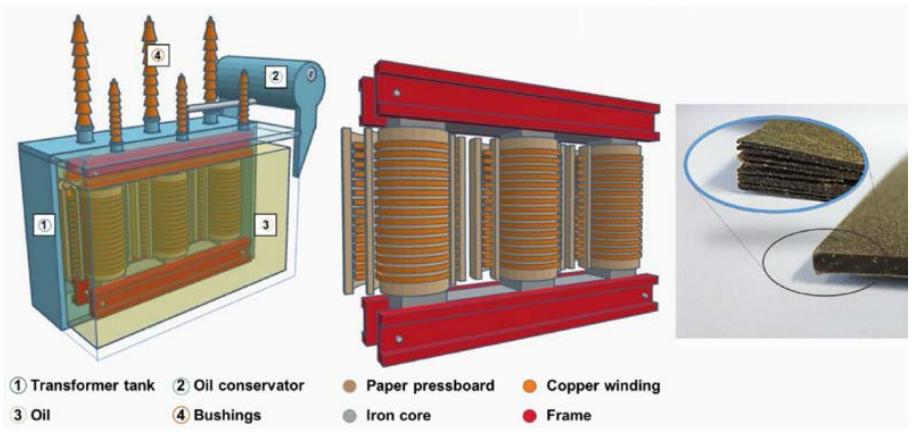

Figure 1:Transformer cellulose paper

The current work proposes an expedient alternative to evaluate the DP in the transformer cellulose paper using a statistical survey. A set of tests were carried out in the laboratory based upon oil and cellulose paper samples of transformers that have aged and also units that were collected from site as a results of various faults. Regression models have been developed to estimate the DP in the cellulose paper using the measured 2FAL concentrations. The results indicate an error of estimate of less than $2 \%$ and $1 \%$ of the proposed logarithmic and polynomial fit DP models against the measured DP respectively.

\section{Furan compounds mechanism}

The Furan compounds present in the transformer oil that can be measured by the High-Performance Liquid Chromatography (HPLC) are namely the 2FAL, 2-Furfurol (2FOL), 5-Hyroxy methyl-2-furfural (5HMF), 5Methyl-2-Furfural (5MEF), and 2acetylfuran (2ACF) as demonstrated in Figure 2 [16].

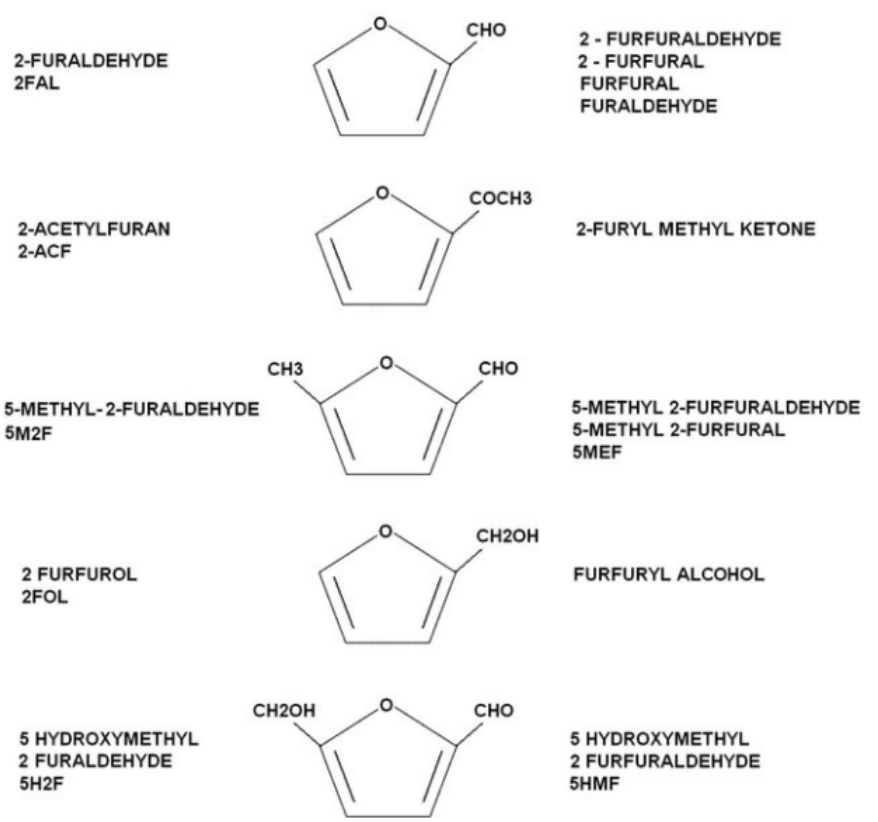

Figure 2: Furan compounds present in the transformer oil.

It is widely adopted the Furans are triggered from the decomposition of cellulose insulating material during the course of the transformer operational lifetime.
In several researches from the literature, case studies of transformer diagnostic status have been presented where the measured concentration of the furan in oil is employed as a key performance indicator of the chemical decomposition of the insulating cellulose paper. Evaluation of the results of furan analysis may be implemented with other assessments such as the monitoring of in-service transformer insulating oil and winding temperatures. As a result of intricacy of the cellulose decomposition mechanics and plethora of factors that can influence the process, the correlation between the 2FAL concentration and the service life of the transformer is not fully unravelled. Based on field experience, the factors that have a material impact on the composition of 2FAL in the transformer insulation oil are summarized below:

- The commencing 2FAL concentration in the transformer oil is characterised by the ratio of the generation/decomposition rate to a particular temperature;

- The occupancy of moisture considerably affect the dissemination of furan compounds between insulating cellulose and oil. The foregoing espouse the 2FAL composition;

- The winding temperature allures the formation / decomposition of 2FAL. The variability of the operating temperature as a result of miscellaneous loading conditions substantially affect the formation of furans;

- Types of transformer oil are also critical on the formulation of 2FAL. Oxidation inhibitors have a particular safeguarding effect on cellulose thermoset and triggers the deceleration of furan compounds in comparison with non-additive oils;

- Thermally upgraded paper generate minimal quantity of furan compounds than standard Kraft paper in oil;

- Types of transformer (cellulose/oil ratio) and cooling state is of paramount importance. Accruing the quantity of cellulose add up to the composition of furans;

- Oil reclamation bring about a lower furan content throughout a lapse of time. However, as a chemical equilibrium, the initial 2FAL concentration will be attained once more.

Several studies have been published in modelling the interrelation between the oil 2FAL concentration and the DP of cellulose material. A universal correlation that is endorsed by the transformer manufacturing industry is presently not available. Nevertheless, there is a common characteristic on the models proposed by authors in [17-21], which concludes that there is a correlation between the 2FAL concentration and the DP of cellulose. Other furan compounds such as 2FOL, 5HMF, 5MEF, and 2ACF are more erratic than 2FAL and tend to decompose rapidly.

Table 1 depicts the DP models that are employed in the comparison approach to substantiate the proposed models. The proposed Eq. (6) and Eq. (7) above are formulated based on logarithmic and polynomial fit regression models using furan analysis data collected from a fleet of mineral oil-filled transformers, particularly in the South African network. These models show excellent correlation coefficient $\left(R^{2}\right)$ between the 2FAL concentration and the DP of cellulose with the polynomial fit model having an improved $R^{2}$. A graphical of these models and existing models is then demonstrated as shown in Figure 3. 
Table 1: Various DP models

\begin{tabular}{|c|c|c|c|}
\hline Eq. & Author & DP experiential formula & Ref. \\
\hline 1 & Chendong & $D P=\frac{\log _{10} 2 F A L-1,51}{-0,0035}$ & [17] \\
\hline 2 & Dong & $D P=402,47-220,87 \times \log _{10} 2 F A L$ & [18] \\
\hline 3 & Vaurchex & $D P=\frac{2,6-\log _{10} 2 F A L}{0,0049}$ & [19] \\
\hline 4 & Heisler & $D P=325 \times\left(\left(\frac{19}{13}\right)-\log _{10} 2 F A L\right)$ & [20] \\
\hline 5 & De Pablo & $D P=\frac{1850}{2 F A L+2,3}$ & [21] \\
\hline 6 & $\begin{array}{l}\text { Thango } \\
\text { (Eq. 6) }\end{array}$ & $\begin{array}{c}D P=-123,6 \times \ln 2 F A L+456,38 \\
R^{2}=0.9809\end{array}$ & \\
\hline 7 & $\begin{array}{l}\text { Thango } \\
\text { (Eq. 7) }\end{array}$ & $\begin{array}{l}D P \\
=0,2358 \times 2 F A L^{6} \\
-5,4819 \times 2 F A L^{5} \\
+49,471 \times 2 F A L^{4} \\
-220,64 \times 2 F A L^{3} \\
+520,55 \times 2 F A L^{2} \\
-692,51 \times 2 F A L+811,15 \\
\quad R^{2}=0,9913\end{array}$ & \\
\hline
\end{tabular}

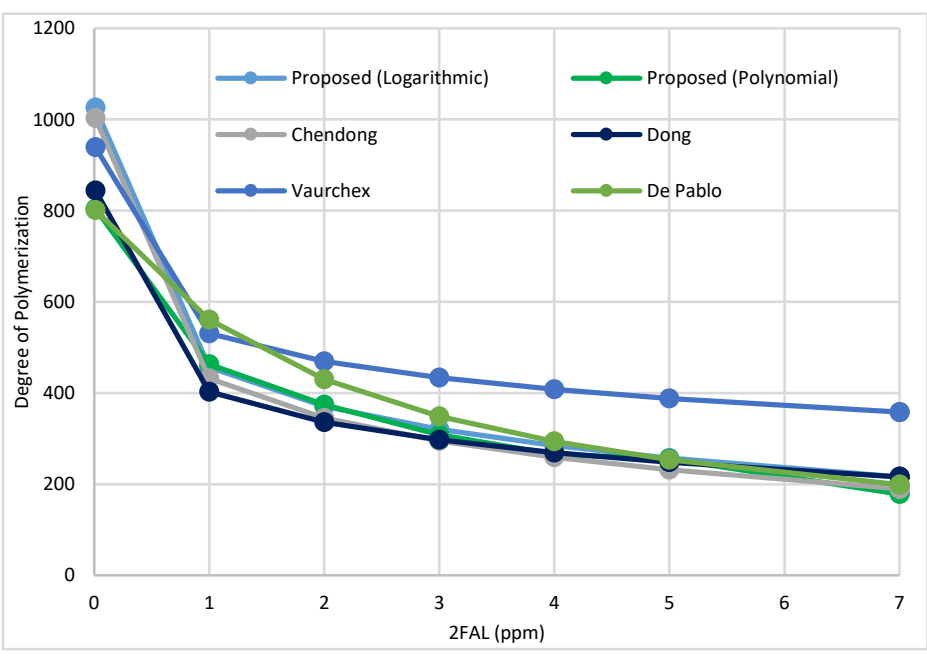

Figure 3: Comparison of DP models

\subsection{Transformer remaining service lifetime}

Consequently, the remaining life of the transformer can determined using Eq. (8), where the DP values range from 1200 ppm to 1000 ppm, with 200 ppm for degraded paper insulation [22].

$$
R S L=20,5 \times \ln \left(\frac{1100}{2 F A L}\right)
$$

The percentage of the decomposed cellulose life for a unit inservice can be ascertained the Eq. (9) and Eq. (10) below.

Table 2: percentage of the decomposed cellulose

\begin{tabular}{|c|c|c|c|}
\hline Eq. & Author & \%RSL experiential formula & Ref. \\
\hline 9 & Kanumuri & $\% R S L=\frac{L O G 10(D P)-2,903}{-0,006021}$ & {$[23]$} \\
& & $\% R S L=166,1 \times \log _{10}(2 F A L)$ & {$[24]$} \\
\hline 10 & Doble & $\frac{132,2}{2}$ & \\
\hline
\end{tabular}

Eq. (9) gives the decomposed cellulose life as a percentage, but to measure transformer paper life in years, Eq. (5) is proposed in [22] may be employed. The parameters used assume initial DP $\left(\mathrm{DP}_{0}\right)$ as 1100 and a 35-year transformer lifespan.

\section{Case Study: South African oil-immersed transformers}

In this section, the sample results of furan analysis of five transformers are presented. The DP has been measured for each of the case studies. At glance, transformer \#5 has the lowest 2FAL concentration with a slightly higher measured DP, which suggest this unit is older than the other units. Additionally, transformer \#2 has a higher 2FAL value and lowest measured DP.

Table 3: Service lifetime parameters

\begin{tabular}{|c|c|c|}
\hline$\#$ & 2FAL & Measured DP \\
\hline 1 & 1,563 & 408 \\
\hline 2 & 0,231 & 648 \\
\hline 3 & 1,601 & 405 \\
\hline 4 & 1,778 & 393 \\
\hline 5 & 2,377 & 351 \\
\hline
\end{tabular}

In Table 4, the proposed models in Eq. (6) and Eq. (7) to evaluate the amount of DP in the transformer insulating cellulose paper are compared with measured data and other models in the literature. The comparison will be carried out based upon the error of estimated of the estimated and measured samples.

Table 5 presents the error of estimate of some case studies using Eq. (6) and Eq. (7) and other DP models from the literature. The 5 cases in Table 3 are employed to examine the accuracy of Eq. (6) and Eq. (7). Only one case (Case 2) shows a slightly higher error of estimate against the measured data, but all the cases for Eq. (6) and Eq. (7) are less than 2\% and $1 \%$ respectively. The error of estimates for Chendong are less than 8\%, Dong less than $12 \%$ except for higher case (case 2), Vaurchex has less than $29 \%$ and De Pablo less than 17\%.

Table 4: Degree of Polymerization

\begin{tabular}{|c|c|c|c|c|c|c|c|c|}
\hline$\#$ & 2FAL & $\begin{array}{c}\text { Measured } \\
\text { DP }\end{array}$ & Thango (Eq. 6) & Thango (Eq. 7) & Chendong & Dong & Vaurchex & De Pablo \\
\hline 1 & 1,563 & 408 & 401 & 406 & 376 & 360 & 491 & 479 \\
\hline 2 & 0,231 & 648 & 637 & 676 & 613 & 543 & 660 & 731 \\
\hline 3 & 1,601 & 405 & 398 & 403 & 373 & 357 & 489 & 474 \\
\hline 4 & 1,778 & 393 & 385 & 390 & 360 & 347 & 480 & 454 \\
\hline 5 & 2,377 & 351 & 349 & 349 & 324 & 319 & 454 & 396 \\
\hline
\end{tabular}


Table 5: Error of estimate (Degree of Polymerization)

\begin{tabular}{|c|c|c|c|c|c|c|}
\hline$\#$ & Thango (Eq. 6) & Thango (Eq. 7) & Chendong & Dong & Vaurchex & De Pablo \\
\hline 1 & $2 \%$ & $1 \%$ & $8 \%$ & $12 \%$ & $20 \%$ & $17 \%$ \\
\hline 2 & $2 \%$ & $4 \%$ & $5 \%$ & $16 \%$ & $2 \%$ & $13 \%$ \\
\hline 3 & $2 \%$ & $1 \%$ & $8 \%$ & $12 \%$ & $21 \%$ & $17 \%$ \\
\hline 4 & $2 \%$ & $1 \%$ & $8 \%$ & $12 \%$ & $22 \%$ & $15 \%$ \\
\hline 5 & $0 \%$ & $1 \%$ & $8 \%$ & $9 \%$ & $29 \%$ & $13 \%$ \\
\hline
\end{tabular}

Table 6: Remnant Service Lifetime

\begin{tabular}{|c|c|c|c|c|c|c|c|c|}
\hline$\#$ & 2FAL & $\begin{array}{c}\text { Measured } \\
\text { DP }\end{array}$ & Thango (Eq. 6) & Thango (Eq. 7) & Chendong & Dong & Vaurchex & De Pablo \\
\hline 1 & 1,563 & 20,33 & 20,68 & 20,46 & 22,01 & 22,92 & 16,53 & 17,05 \\
\hline 2 & 0,231 & 10,85 & 11,18 & 9,97 & 11,98 & 14,47 & 10,46 & 8,38 \\
\hline 3 & 1,601 & 20,48 & 20,83 & 20,60 & 22,17 & 23,05 & 16,62 & 17,25 \\
\hline 4 & 1,778 & 21,10 & 21,51 & 21,27 & 22,90 & 23,64 & 17,02 & 18,16 \\
\hline 5 & 2,377 & 23,42 & 23,51 & 23,54 & 25,06 & 25,35 & 18,15 & 20,97 \\
\hline
\end{tabular}

Table 7: Percentage Remnant Service Lifetime (Eq. 9)

\begin{tabular}{|c|c|c|c|c|c|c|c|c|}
\hline$\#$ & 2FAL & $\begin{array}{c}\text { Measured } \\
\text { DP }\end{array}$ & Thango (Eq. 6) & Thango (Eq. 7) & Chendong & Dong & Vaurchex & De Pablo \\
\hline 1 & 1,563 & 48,55 & 49,77 & 48,99 & 54,44 & 57,66 & 35,19 & 37,00 \\
\hline 2 & 0,231 & 15,18 & 16,36 & 12,09 & 19,16 & 27,93 & 13,81 & 6,50 \\
\hline 3 & 1,601 & 49,09 & 50,31 & 49,51 & 55,02 & 58,12 & 35,51 & 37,70 \\
\hline 4 & 1,778 & 51,26 & 52,69 & 51,85 & 57,58 & 60,18 & 36,89 & 40,90 \\
\hline 5 & 2,377 & 59,41 & 59,74 & 59,86 & 65,18 & 66,21 & 40,87 & 50,79 \\
\hline
\end{tabular}

Table 8: Percentage Remnant Service Lifetime (Eq. 10)

\begin{tabular}{|c|c|c|c|c|c|c|c|c|}
\hline$\#$ & 2FAL & $\begin{array}{c}\text { Measured } \\
\text { DP }\end{array}$ & Thango (Eq. 6) & Thango (Eq. 7) & Chendong & Dong & Vaurchex & De Pablo \\
\hline 1 & 1,563 & 51,43 & 50,21 & 50,99 & 45,54 & 42,33 & 64,79 & 62,99 \\
\hline 2 & 0,231 & 84,80 & 83,62 & 87,89 & 80,83 & 72,05 & 86,18 & 93,49 \\
\hline 3 & 1,601 & 50,90 & 49,68 & 50,47 & 44,97 & 41,86 & 64,48 & 62,28 \\
\hline 4 & 1,778 & 48,73 & 47,29 & 48,13 & 42,41 & 39,80 & 63,09 & 59,08 \\
\hline 5 & 2,377 & 40,58 & 40,24 & 40,12 & 34,80 & 33,77 & 59,12 & 49,20 \\
\hline
\end{tabular}

After examining the veracity of Eq. (6) and Eq. (7) to evaluate the DO, the remnant service lifetime of the insulating cellulose paper was established, at which point, the studied transformers was determined by applying Eq. (8). Table 6 shows the corresponding remnant service lifetime of the transformer.

Table 7 and Table 8 demonstrate the percentage remnant service lifetime of the 5 cases in Table 6 . The results indicate that there is an inversely proportionate relationship between the percentage remnant service lifetime and the 2FAL concentration while a directly proportional relationship is observed against the degree of polymerization. The results of the percentage remnant service lifetime by applying Eq. (9) is tabulated below.

An increase in the 2FAL concentration results in the decrease of the degree of polymerization and consequently the transformer's remnant in-service lifetime. The degree of polymerization of insulating cellulose paper is high for newly manufactured transformers ranging above 800 to 1200 and the cellulose paper with decomposition activity due to the operational conditions will decrease radically until it reaches a DP of about 2000 where the unit must be removed from service as it indicates end of lifespan. Subsequently, the results of the percentage remnant service lifetime by applying Eq. (10) is tabulated.

Based on the results presented in Table 7 and Table 8, it can be observed and concluded that the proposed Eq. (6) and Eq. (7) may be adopted by local manufactures to reliably evaluate the remnant in-service lifetime of transformers connected to the South African grid. Results of Chendong, Dong, Vaurchex and De Pablo are erratic in evaluating the transformer service life.

\section{Conclusion}

Examination of cellulose paper in transformers is highly complex when the unit is in-service, consequently chemical tests were conducted to survey the condition of the insulating cellulose paper. The degree of polymerization was wielded as a key benchmark for evaluating the condition of the cellulose paper by measuring the Furan (2FAL) concentration. A statistical survey through logarithmic and polynomial fit regression models was realized to develop the prognosis equations allying the degree of polymerization and the measured 2FAL concentration. The statistical survey results demonstrated that there is a high correlation between the cellulose DP and the 2FAL concentration, 
yielding correlation coefficients of 0.9809 and 0.9913 for the proposed models.

The results of the studied cases inveterate that the 2FAL concentration is a suitable index for predicting the degree of polymerization. By comparing the proposed models in Eq. (6) and Eq. (7) with the DP models in the literature, the results revealed that the proposed DP models based on South African transformers to be an excellent measure of the degree of polymerization at which point the remnant and percentage service lifetime of the units can be evaluated. The error of estimate of the proposed Eq. (6) and measured data is less than $2 \%$ while Eq. (7) is less than $1 \%$ except for an anomaly observed in case number 2 . Chendong, Dong, Vaurchex and De Pablo yielded and error of estimate of no more than $8 \%, 16 \%, 29 \%$ and $17 \%$ in comparison to the measured data. Similar trends in the estimation of the remnant and percentage service lifetime are observed.

The continuation of this work in the future will comprise the application of least squares support vector machine for classifying the condition of the insulating cellulose paper and then evaluate the remnant service lifetime of a transformer.

\section{Conflict of Interest}

The authors declare no conflict of interest.

\section{References}

[1] M. K. Pradhan and T. S. Ramu, "Diagnostic testing of oil-impregnated paper insulation in prorated power transformers under accelerated stress," Conference Record of the 2004 IEEE International Symposium on Electrical Insulation, 66-69, , 2004, doi: 10.1109/ELINSL.2004.1380452.

[2] C. Chakradhar Reddy, E. Johnson and T. S. Ramu, "On the life estimation of oil impregnated paper insulated transformer bushings," 2007 Electrical Insulation Conference and Electrical Manufacturing Expo, 13-16, 2007, doi: 10.1109/EEIC.2007.4562578.

[3] Y. Tu, W. Sun, C. Yue, G. Chen and W. Wang, "Research of insulation properties of polymer materials using in oil-filled transformers under high temperature," 2011 Annual Report Conference on Electrical Insulation and Dielectric Phenomena, 583-586, 2011, doi: 10.1109/CEIDP.2011.6232724.

[4] S. Missas, M. G. Danikas and I. Liapis, "Factors affecting the ageing of transformer oil in $150 / 20 \mathrm{kV}$ transformers," 2011 IEEE International Conference on Dielectric Liquids, 1-4, 2011, doi: 10.1109/ICDL.2011.6015409.

[5] T. K. Saha, M. Darveniza, Z. T. Yao, D. J. T. Hill and G. Yeung, "Investigating the effects of oxidation and thermal degradation on electrical and chemical properties of power transformers insulation," in IEEE Transactions on Power Delivery, 14(4), 1359-1367, 1999, doi: 10.1109/61.796229.

[6] D. M. Mehta, P. Kundu, A. Chowdhury and V. K. Lakhiani, "DGA diagnostics save transformers - case studies," 2015 International Conference on Condition Assessment Techniques in Electrical Systems (CATCON), 116-120, 2015, doi: 10.1109/CATCON.2015.7449519.

[7] S. Apte, R. Somalwar and A. Wajirabadkar, "“'Incipient Fault Diagnosis of Transformer by DGA Using Fuzzy Logic”," 2018 IEEE International Conference on Power Electronics, Drives and Energy Systems (PEDES), 15, 2018, doi: 10.1109/PEDES.2018.8707928.

[8] K. Baburao, N. M. Bhangre, A. M. Wagle, A. Venkatasami and S. E. Chaudhari, "The experience of DP and furan in remnant life assessment of power transformer," 2008 International Conference on Condition Monitoring and Diagnosis, 555-558, 2008, doi: 10.1109/CMD.2008.4580348.

[9] N. Das, A. Abu-Siada and S. Islam, "New approach to estimate furan contents in transformer oil using spectroscopic analysis," $201222^{\text {nd }}$ Australasian Universities Power Engineering Conference (AUPEC), pp. 14, 2012.

[10] S. P. Lai, A. Abu-Siada, S. M. Islam and G. Lenco, "Correlation between UV-Vis spectral response and furan measurement of transformer oil," 2008
International Conference on Condition Monitoring and Diagnosis, 659-662, 2008, doi: 10.1109/CMD.2008.4580372.

[11] D. Feng, Z. Wang and P. Jarman, "Transmission power transformer assessment using furan measurement with the aid of thermal model," 2012 IEEE International Conference on Condition Monitoring and Diagnosis, 521-524, 2012, doi: 10.1109/CMD.2012.6416194.

[12] M. Meissner, M. Darmann, S. Schober, M. Mittelbach and C. Sumereder, "Reliability Study of Furan Level Analysis for Transformer Health Prediction," 2019 IEEE 20th International Conference on Dielectric Liquids (ICDL), 1-4, 2019, doi: 10.1109/ICDL.2019.8796785.

[13] K. B. Shaban, A. H. El-Hag and K. Benhmed, "Prediction of Transformer Furan Levels," in IEEE Transactions on Power Delivery, 31(4), 1778-1779, 2016, doi: 10.1109/TPWRD.2016.2521320.

[14] M. A. Talib, M. A. A. Aziz, Y. Balasubramaniam, Y. Z. Y. Ghazali, M. R. Z. Abidin and M. F. M. Yousof, "Transformer Ageing Investigation and Correlation of Furanic Compound and Degree of Polymerization for Power Transformer Life Assessment," 2020 IEEE International Conference on Power and Energy (PECon), 240-244, 2020, doi: 10.1109/PECon48942.2020.9314543.

[15] "IEEE Guide for Evaluation and reconditioning of Liquid Immersed Power Transformers," in IEEE Std. C57.140-2006, 1-73, 2007, doi: 10.1109/IEEESTD.2007.353650

[16] I. Hohlein and A. J. Kachler, "Aging of cellulose at transformer service temperatures. Part 2. Influence of moisture and temperature on degree of polymerization and formation of furanic compounds in free-breathing systems," in IEEE Electrical Insulation Magazine, 21(5), 20-24, 2005, doi: 10.1109/MEI.2005.1513426.

[17] X. Chendong, F. Qiming, X. Shiheng, “To Estimate the Ageing Status of Transformers by Furfural Concentration in the Oil”, In Proceedings of the CIGRE Study Committee 33 Colloquium, Leningrad, Moscow; 1991.

[18] M. Dong, Z. Yan and G. J. Zhang, "Comprehensive diagnostic and aging assessment method of solid insulation in transformer," 2003 Annual Report Conference on Electrical Insulation and Dielectric Phenomena, 137-140, 2003, doi: 10.1109/CEIDP.2003.1254813.

[19] H. Vaurchex, I. Höhleim and A. J. Kachler, "Transformer aging research on furanic compounds dissolved in insulating oil”, CIGRE, 2002, doi: publication/15-302_2002-transformer-ageing-research-on-furaniccompounds-dissolved-in-insulating-oil

[20] H. Andreas et al. "Zustandsbeurteilung von Transformatoren mit FurfurolBestimmung.” 2003.

[21] A. de Pablo, "Furfural and ageing: how are they related," IEE Colloquium on Insulating Liquids (Ref. No. 1999/119), 5/1-5/4, 1999, doi: 10.1049/ic:19990667.

[22] M. K. Pradhan and T. S. Ramu, "On the estimation of elapsed life of oilimmersed power transformers," in IEEE Transactions on Power Delivery, 20 (3), 1962-1969, 2005, doi: 10.1109/TPWRD.2005.848663.

[23] D. Kanumuri, V. Sharma, O.P. Rahi, O P, "Analysis Using Various Approaches for Residual Life Estimation of Power Transformers", International Journal on Electrical Engineering and Informatics, Bandung 11(2), 389-407, 2019, doi:10.15676/ijeei.2019.11.2.11.

[24] Doble,” Testing \& Sampling”, doi: services/laboratory-services/testing-andsampling/. 